\title{
Cognitive function in Hashimoto's thyroiditis under levothyroxine treatment
}

\author{
Vaitsa Giannouli, ${ }^{1}$ Konstantinos A. Toulis, ${ }^{2}$ Nikolaos Syrmos ${ }^{3}$ \\ ${ }^{1}$ Medical School, Aristotle University of Thessaloniki; ${ }^{2}$ Department of Endocrinology, 424 General Army Hospital; \\ ${ }^{3}$ AHEPA Hospital, Aristotle University of Thessaloniki; Thessaloniki, Greece
}

\begin{abstract}
OBJECTIVE: Although overt hypothyroidism has been documented as exerting detrimental effects on cognition and behavior, it remains controversial whether subclinical hypothyroidism or euthyroid patients with Hashimoto's thyroiditis (HT) under levothyroxine (LT4) treatment may experience any noticeable decline in cognitive function. PATIENTS: Two otherwise healthy, highly-functioning, first-degree relatives with a diagnosis of HT, under LT4 treatment for two years, were prospectively recruited into a clinical research study setting and followed for a year. MEASUREMENTS: Thyroid functions tests and a detailed battery of tests assessing global cognitive status, attention, verbal and working memory, visuoperceptual skills, executive functions and mood were performed at baseline and at one year after recruitment. RESULTS: Overall, patients' performance on the neuropsychological battery was good and, in the majority of cognitive functions, their performance could be characterized as exceptional. No noticeable changes in any of the studied parameters were detected. CONCLUSIONS: The present case study failed to detect any noticeable changes in the cognitive and emotional function of two women with HT under LT4 treatment. The course of cognitive function of the two HT patients, evaluated by a detailed battery of tests, tends to confirm the benign nature of HT.
\end{abstract}

Key words: Hashimoto's thyroiditis, Neuropsychology, LT4 treatment

Chronic autoimmune (Hashimoto's) thyroiditis (HT) is the most common thyroid disorder in iodine-sufficient areas. HT is marked by the presence of complement-fixing autoantibodies to thyroid peroxidase (TPOabs) which tend to correlate with progressive thyroidal damage ${ }^{1}$ and may lead to sub-

Address for correspondence:

Vaitsa Giannouli, School of Medicine, Aristotle University of Thessaloniki, Greece, E-mail: giannouliv@hotmail.com

Received: 30-11-2013, Accepted: 16-01-2014 clinical and overt hypothyroidism. Thyroid hormone deficiency (overt hypothyroidism) has profound and multi-systemic detrimental effects from which brain and behavior are not spared. The latter may relate to global cognitive, behavioral and emotional changes, including depression. ${ }^{2}$ This is not the case for subclinical hypothyroidism and euthyroid HT, whether under levothyroxine (LT4) treatment or not, the effect of which on cognitive performance is somewhat controversial. Whereas it has been suggested that "a state of brain hypothyroidism in the context of systemic 
euthyroidism"3 and an association between thyroid autoimmunity and cognitive function may exist, ${ }^{4}$ and that neurocognitive functioning and psychological well-being may not be completely restored in patients with hypothyroidism despite LT4 treatment, ${ }^{5}$ neither was an association between indices of depression and thyroid autoimmunity established in a population study ${ }^{6}$ nor did treatment with levothyroxine for a year improve any parameters of cognitive functioning in patients with subclinical hypothyroidism. ${ }^{7}$

Our aim was to test: 1) whether LT4 treatment improves the profile of first degree relatives as to different aspects of cognition and emotion, and 2) whether euthyroidism under LT4 treatment (and manifesting with depressive symptomatology) leads to neuropsychological deficits.

Two otherwise healthy, highly-functioning, firstdegree relatives [daughter (A) and mother (B)] with a diagnosis of HT under LT4 treatment were recruited into a clinical research study setting.

Patient A, at the time of the first neuropsychological testing (initial assessment in 2010) was a 25 -year old, right-handed woman on therapy for Hashimoto's thyroiditis during the last two years. She was a Social Sciences postgraduate student of a Greek university and had had her first neuropsychological examination because of personal complaints concerning her low mood and experiences of fatigue, but also due to fears about the diagnosis of her disease.

Patient $\mathrm{B}$, the mother of patient $\mathrm{A}$, was a righthanded woman, 62 years old at the time of the initial examination. She was first diagnosed with Hashimoto's thyroiditis five years previously, whereas treatment was instituted two years ago (due to self-perceived physical and cognitive disturbances). Patient B, a divorced woman, had completed sixteen years of education (including university studies), which she completed - as had her daughter - with honors and distinction.

The women shared a familial history of relatives suffering from thyroid disorders (e.g. goiter). Neither woman had been diagnosed with other somatic health problems, with the exception of patient A's irregular menstrual cycle. The two patients at the time of the two examinations (test and retest after a year's inter- val) repeated their thyroid hormone function tests.

Both patients were on treatment with synthetic T4 (levothyroxine sodium): patient A was on a daily dose of $62 \mathrm{mcg}$, which after TSH re-assessment was modified to $88 \mathrm{mcg}$ and patient B had been on $100 \mathrm{mcg}$ for two years before the initial examination.

At baseline, a detailed neuropsychological assessment (including evaluation of attention, verbal memory, working memory, visuoperceptual skills and executive functions) was carried out along with a brain magnetic resonance and an assessment of the patients' thyroid function status (chemiluminescent immunoassay). Full neuropsychological assessment and selected thyroid functions tests were repeated one year after the recruitment.

Results of the cognitive and emotional examination (test and retest) along with thyroid function tests are summarized in Table 1 and 2, respectively. At baseline, patient B was found to be over-treated. The emotional profile of both women suggested depressive symptomatology. On the basis of the finding of a collection of signs and symptoms (DSM-IV-TR criteria), patient A was also diagnosed with major depressive disorder. Computerized tomography (CT) and magnetic resonance imaging (MRI) at the time of the first neuropsychological examination were normal for both women with no detectable brain damage. Overall, patient A's and B's performance on the neuropsychological battery was good and in the majority of cognitive functions their performance could be characterized as exceptional. No noticeable changes in any of the studied parameters were detected.

The present case study failed to detect any noticeable changes in the cognitive function of two women with HT under LT4 treatment. The course of cognitive function of the two HT patients, evaluated by a detailed battery of tests, tends to confirm the benign nature of HT. Notably, patient A, who was diagnosed with major depressive disorder and was thus expected to demonstrate cognitive impairment (mainly deficits in attention, memory and executive functioning), was found to be resistant to even subtle changes. Patient $\mathrm{B}$ was also found to lack psychomotor slowing and impairments in memory and executive functioning. These are unusual and reassuring findings, which are in 
Table 1. Summary of cognitive and emotional examination for patients A and B (first assessment and at one-year follow-up)

\begin{tabular}{|c|c|c|c|c|}
\hline Tests & First assessment A & Follow-up A & First assessment B & Follow-up B \\
\hline \multicolumn{5}{|l|}{ Global Cognitive Status } \\
\hline Mini-Mental State Examination & $30 / 30$ & $30 / 30$ & $29 / 30$ & $30 / 30$ \\
\hline \multicolumn{5}{|l|}{ Attention } \\
\hline Trail-Making Test Part A & $80^{\text {th }}$ percentile & $>90^{\text {th }}$ percentile & $80^{\text {th }}$ percentile & $80^{\text {th }}$ percentile \\
\hline $\begin{array}{l}\text { Ruff } 2 \& 7 \text { Selective Attention Test } \\
\text { Automatic detection speed }\end{array}$ & $95^{\text {th }}$ percentile & $95^{\text {th }}$ percentile & $95^{\text {th }}$ percentile & $95^{\text {th }}$ percentile \\
\hline Automatic detection accuracy & $95^{\text {th }}$ percentile & $95^{\text {th }}$ percentile & $95^{\text {th }}$ percentile & $95^{\text {th }}$ percentile \\
\hline Controlled search speed & $95^{\text {th }}$ percentile & $95^{\text {th }}$ percentile & $95^{\text {th }}$ percentile & $95^{\text {th }}$ percentile \\
\hline Controlled search accuracy & $95^{\text {th }}$ percentile & $95^{\text {th }}$ percentile & $95^{\text {th }}$ percentile & $95^{\text {th }}$ percentile \\
\hline Digit Span Forward & 10 & 9 & 8 & 9 \\
\hline Stroop Word & $80^{\text {th }}$ percentile & $90^{\text {th }}$ percentile & $80^{\text {th }}$ percentile & $80^{\text {th }}$ percentile \\
\hline Color & $80^{\text {th }}$ percentile & $90^{\text {th }}$ percentile & $80^{\text {th }}$ percentile & $80^{\text {th }}$ percentile \\
\hline Color/Word & $80^{\text {th }}$ percentile & $90^{\text {th }}$ percentile & $80^{\text {th }}$ percentile & $80^{\text {th }}$ percentile \\
\hline Spatial Span & 8 & 8 & 6 & 7 \\
\hline \multicolumn{5}{|l|}{ Verbal Memory } \\
\hline Word List Learning Immediate & $37 / 40$ & $38 / 40$ & $35 / 40$ & $33 / 40$ \\
\hline Delayed & $8 / 10$ & $9 / 10$ & $7 / 10$ & $7 / 10$ \\
\hline Word recognition & $20 / 20$ & $20 / 20$ & $20 / 20$ & $20 / 20$ \\
\hline Stories Learning Immediate & $16 / 16$ & $15 / 16$ & $15 / 16$ & $16 / 16$ \\
\hline Delayed & $15 / 16$ & $15 / 16$ & $14 / 16$ & $15 / 16$ \\
\hline \multicolumn{5}{|l|}{ Working Memory } \\
\hline Trail-Making Test Part B & $80^{\text {th }}$ percentile & $80^{\text {th }}$ percentile & $80^{\text {th }}$ percentile & $80^{\text {th }}$ percentile \\
\hline Digit Span Backward & 7 & 8 & 7 & 5 \\
\hline \multicolumn{5}{|l|}{ Visuoperceptual Skills } \\
\hline Rey-Osterrieth Complex Figure Immediate Recall & $35 / 36$ & $35 / 36$ & $33 / 36$ & $32 / 36$ \\
\hline Delayed Recall & $34 / 36$ & $35 / 36$ & $30 / 36$ & $32 / 36$ \\
\hline Recognition & $12 / 12$ & $12 / 12$ & $12 / 12$ & $12 / 12$ \\
\hline \multicolumn{5}{|l|}{ Executive Functions } \\
\hline Semantic Fluency (total number of words) & $90^{\text {th }}$ percentile & $90^{\text {th }}$ percentile & $80^{\text {th }}$ percentile & $80^{\text {th }}$ percentile \\
\hline Phonological Fluency (total number of words) & $80^{\text {th }}$ percentile & $90^{\text {th }}$ percentile & $90^{\text {th }}$ percentile & $90^{\text {th }}$ percentile \\
\hline \multicolumn{5}{|l|}{ Mood } \\
\hline Center for Epidemiologic Studies-Depression Scale & $40 / 60$ & $43 / 60$ & $15 / 60$ & Declined \\
\hline Geriatric Depression Scale & - & - & $5 / 15$ & $4 / 15$ \\
\hline
\end{tabular}

discordance with previous reports not only for patients with HT and on LT4 treatment ${ }^{5}$ but also for patients suffering depressive symptomatology ${ }^{8}$ in whom poor performance (below normal) in various domains of neurocognitive functioning have been tentatively determined. These hypotheses should be further investigated in future quantitative experimental studies. Furthermore, according to Panicker, ${ }^{9}$ various types of thyroid dysfunction (e.g. hypothyroidism) are usually found in first-degree relatives, such as mothers and daughters. A similar hypothesis in genetics has been proposed as regards $\mathrm{IQ}^{10}$ where correlations between sons with their fathers' IQs are the lowest $(r=.44)$, while the correlations between mothers and daughters' IQs are the highest [at about $r=.68$ ]. Accordingly, a potential objective for future research is to focus on 
Table 2. Thyroid function tests for patients A and B (first assessment and at one-year follow-up)

\begin{tabular}{lccccc}
\hline & Normal values & First assessment A & Follow-up A & First assessment B & Follow-up B \\
\hline BMI $\left(\mathrm{kg} / \mathrm{m}^{2}\right)$ & & 22 & 22 & 23 & 23 \\
TSH $(\mu \mathrm{IU} / \mathrm{ml})$ & $0.3-5$ & 2.57 & 0.49 & 0.02 & 0.23 \\
fT4 $(\mathrm{ng} / \mathrm{dl})$ & $0.8-2$ & 1.22 & & 1.62 & \\
fT3 $(\mathrm{pg} / \mathrm{ml})$ & $2-4.8$ & 3 & & 2.84 & \\
T4 $(\mu \mathrm{g} / \mathrm{dl})$ & $5-12$ & & 6.43 & & \\
Anti-TPO $(\mathrm{IU} / \mathrm{ml})$ & $0-100$ & 3700 & 584 & 1680 & 2300 \\
Anti-TG $(\mathrm{IU} / \mathrm{ml})$ & $0-150$ & 351 & 275 & $>4000$ & $>4000$ \\
B12 $(\mathrm{ng} / \mathrm{ml})$ & $200-870$ & 393 & 400 & 374 & 400 \\
\hline
\end{tabular}

Anti-TG: thyroglobulin antibodies; Anti-TPO: thyroid peroxidase antibodies; BMI: body mass index; B12: vitamin B12; fT4: free thyroxine; fT3: free triidothyronine; T4: thyroxine; TSH: thyrotropin.

unveiling the way(s) that first-degree relatives react to hormonal supplements and changes in their cognitive status, which may be linked in some hereditary genetic way, especially with regard to female relatives.

\section{CONFLICT OF INTEREST}

None

\section{FUNDING}

None

\section{REFERENCES}

1. Marino M, Latrofa F, Barbesino G, Chiovato L, 1999 Pathogenetic and clinical aspects of autoimmune thyroiditis. Exp Clin Endocrinol Diabetes 107: Suppl 3: 79-83.

2. Carta MG, Loviselli A, Hardoy MC, et al, 2004 The link between thyroid autoimmunity (antithyroid peroxidase autoantibodies) with anxiety and mood disorders in the community: a field of interest for public health in the future. BMC Psychiatry 4: 25.
3. Jackson IM, 1998 The thyroid axis and depression. Thyroid 8: 951-956.

4. Grigorova M, Sherwin BB, 2012 Thyroid hormones and cognitive functioning in healthy, euthyroid women: a correlational study. Horm Behav 61: 617-622.

5. Wekking EM, Appelhof BC, Fliers E, et al, 2005 Cognitive functioning and well-being in euthyroid patients on thyroxine replacement therapy for primary hypothyroidism. Eur J Endocrinol 153: 747-753.

6. Engum A, Bjoro T, Mykletun A, Dahl AA, 2005 Thyroid autoimmunity, depression and anxiety; are there any connections? An epidemiological study of a large population. J Psychosom Res 59: 263-268.

7. Jorde R, Waterloo K, Storhaug H, Nyrnes A, Sundsfjord J, Jenssen TG, 2006 Neuropsychological function and symptoms in subjects with subclinical hypothyroidism and the effect of thyroxine treatment. J Clin Endocrinol Metab 91: 145-153.

8. Veiel HO, 1997 A preliminary profile of neuropsychological deficits associated with major depression. J Clin Exp Neuropsychol 19: 587-603.

9. Panicker V, 2011 Genetics of thyroid function and disease. The Clin Bioch Rev 32: 165.

10. Lehrke R 1997 Sex linkage of intelligence. The X-factor. London: Praeger. 